\title{
Equilibrium Studies of Cobalt (II) and Copper (II) with Diethylene Triamine Penta Acetic Acid (DTPA)
}

\author{
Gurveer Singh Dhaliwal
}

Assistant Professor, Department of Applied Sciences, Chandigarh Engineering College, Landran Mohali (Pb.)

\begin{abstract}
Biologically important complexes involving DTPA have been investigated potentiometrically in aqueous medium under the well-defined condition of temperature and ionic strength. SCOGS computer program is used to obtain the speciation of various protonated, nonprotonated binary and ternary species formed in a particular equilibrium. The percentage formation of complexes is appreciably high which is evident from speciation curves. The stability constants and thermodynamic parameters $\Delta G^{\circ}, \Delta H^{\circ}$, and $\Delta S^{\circ}$ support the favourable formation of mixed metal species. Negative values of $\Delta$ logK indicates higher stability of ternary species.
\end{abstract}

Keyword: Equilibrium Studies, DTPA, SCOGS, Cobalt, Copper

\section{Introduction}

Recently there has been considerable interest in the study of binary, ternary and quaternary complexes by $\mathrm{pH}$-metric method [1-3]. The metal complexes play an important role in various fields of biological, analytical, industrial and medicinal chemistry. Biological system contains various essential and nonessential or potentially toxic metal ions $[4,5]$.

Some publications on multiple equilibria and chemical distribution of biometals with some biologically potential ligands is worth mentioning [6, 7]. Heterobinuclear complexes of transition metals have been investigated by Nair and his group [8].. Few interesting investigations on heterobimetallic complexes having Mixed-ligand, mixedmetal complexes involving more than one metal ions of the same or different types may prove as better models for multimetal multiligand equilibria occurring in the biological systems may be reported in 2014 [ 9-10]. Chemical literature reveals that although mixed ligand systems have been explored extensively, but equilibrium studies on mixed metal complexes have gained attention in recent past $[8,11-12]$

In the present work some metal complex equilibria involving DTPA are investigated. The metal chosen for the present studies are $\mathrm{Co}$ (II) and $\mathrm{Cu}$ (II).

\section{Experimental}

All the chemicals used were of highest purity Merck/Aldrich product. Solution of disodium salt of DTPA was prepared by dissolving accurately weighed amount of acid (A.R) in two equivalents of standard sodium hydroxide $(0.10 \mathrm{M})$ to get a solution of $0.01 \mathrm{M}$. All other solutions were prepared by standard method in deionised water having $\mathrm{pH} \sim 6.8$.

The protonation and coordination equilibriums were investigated by $\mathrm{pH}$ - metric titration in aqueous medium. An Elico digital $\mathrm{pH}$-meter model LI-127 with ATC probe and combined electrode type (CL-51B-Glass Body; range 0-14 pH unit; $0-100^{\circ} \mathrm{C}$ Automatic/manual) with accuracy \pm
0.01 was employed for $\mathrm{pH}$ measurement throughout the present work.

Following sets of titration mixture were prepared, keeping total volume $50 \mathrm{~mL}$ and titrated against $0.10 \mathrm{M} \mathrm{NaOH}$ solution at two different temperatures (i.e. $20 \pm 1^{\circ} \mathrm{C}$ and $\left.30 \pm 1^{\circ} \mathrm{C}\right)$ and three different ionic strengths $(\mu=0.05 \mathrm{M}$, $0.10 \mathrm{M}, 0.15 \mathrm{M})$ maintained by $\mathrm{NaNO} 3$ :

1. Acid titration: $\mathrm{HNO} 3\left(2.0 \times 10^{-3} \mathrm{M}\right)$.

2. ((Ligand ' $A$ ' titration: HNO3 $\left(2.0 \times 10^{-3} \mathrm{M}\right)+$ Ligand ' $A$ ' $\left(1.0 \times 10^{-3} \mathrm{M}\right)$.

3. Metal (M)-Ligand ' $A$ ' $(1: 1)$ titration: HNO3 $(2.0 \times 10$ $\left.{ }^{3} \mathrm{M}\right)+$ Ligand ' $\mathrm{A}$ ' $\left(1.0 \times 10^{-3} \mathrm{M}\right)+$ Metal nitrate $\left(1.0 \times 10^{-}\right.$ $\left.{ }^{3} \mathrm{M}\right)$.

4. Metal (M')-Ligand(1:1) titration: $\operatorname{HNO} 3\left(2.0 \times 10^{-3} \mathrm{M}\right)+$

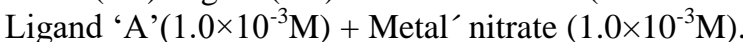

5. Metal (M) - Metal (M') -Ligand(1:1:1) titration: HNO3 $\left(2.0 \times 10^{-3} \mathrm{M}\right)+$ Ligand 'A' $\left(1.0 \times 10^{-3} \mathrm{M}\right)+$ Metal

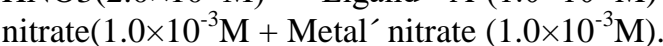

Where, ligand 'A' = DTPA (Diethylene triamine penta acetic acid) and $/ \mathrm{M}^{\prime}=\mathrm{Co}$ (II) and $\mathrm{Cu}$ (II)

Volume of alkali used in each set of titration is converted into moles of alkali per mole of ligand / metal and is denoted as 'a'. Representative titration curves are given in the form of Figure 1. 


\section{International Journal of Science and Research (IJSR) \\ ISSN (Online): 2319-7064}

Index Copernicus Value (2013): 6.14 | Impact Factor (2015): 6.391

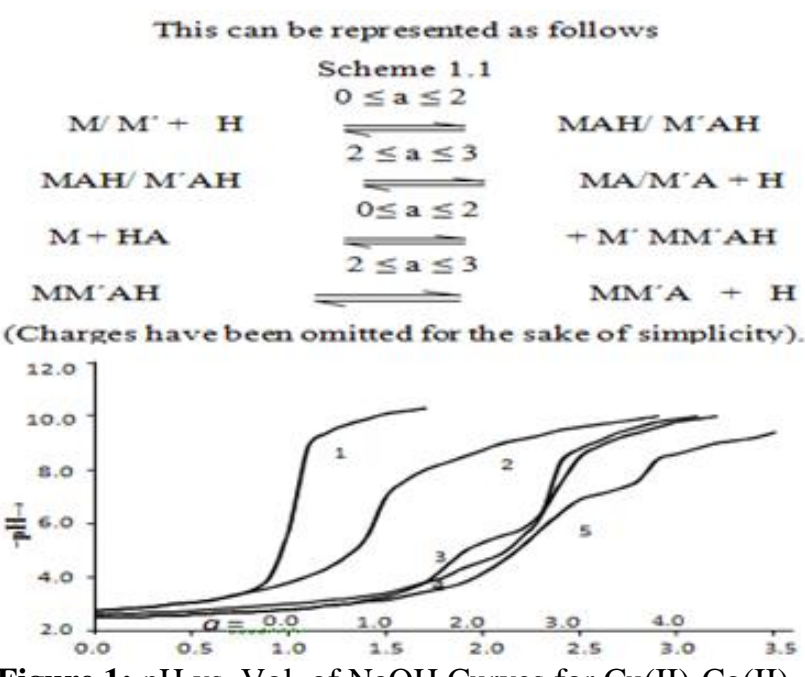

Figure 1: pH vs. Vol. of $\mathrm{NaOH}$ Curves for $\mathrm{Cu}(\mathrm{II})-\mathrm{Co}(\mathrm{II})-$

DTPA (1:1:1) System at $30^{\circ} \mathrm{C}[\mu=0.10 \mathrm{M}$ NaNO3) $]$

Curve 1 represents Acid titration curve.

Curve 2 represents Ligand 'A' (DTPA) titration curve.

Curve 3 represent Metal (M)-Ligand 'A' (1:1) titration curve.
Curve 4 represents Metal' (M')-Ligand 'A' (1:1) titration curve.

Curve 5 represents Mixed Metal (1:1:1) titration curve.

The protonation constants of ligand and formation constants of binary and ternary systems were calculated by method of Chaberek and Martell [13-14] as modified by Nayan and Dey [15] and values were refined by SCOGS computer program [16-17]. Thermodynamic formation constants were obtained by extrapolating the $\log \beta$ vs $\gamma_{\mu}$ plot to zero ionic strength. The values are given in Tables $1,2 \& 3$.

Table-1: Dissociation constants of ligand $(\log \beta \mu \rightarrow 0)$.

\begin{tabular}{ccc}
\hline \multirow{2}{*}{ Parameter } & \multicolumn{2}{c}{ DTPA } \\
\cline { 2 - 3 } & $20^{\circ} \mathrm{C}$ & $30^{\circ} \mathrm{C}$ \\
\hline $\log \beta \mathrm{HA}$ & 9.81 & 9.66 \\
$\log \beta \mathrm{H} 2 \mathrm{~A}$ & 17.68 & 17.50 \\
$\log \beta \mathrm{H} 3 \mathrm{~A}$ & 21.35 & 20.97 \\
\hline
\end{tabular}

Table 2: Thermodynamic formation constants of metal- ligand complexes of M(II)/M'(II)-DTPA in equimolar systems

\begin{tabular}{|c|c|c|c|c|}
\hline Parameters & \multicolumn{2}{|c|}{ corin } & \multicolumn{2}{|c|}{ Custi) } \\
\hline $\log \beta_{\text {MAง }}$ & $20^{\circ} \mathrm{C}$ & $30^{\circ} \mathrm{C}$ & $20^{\circ} \mathrm{C}$ & $30^{\circ} \mathrm{C}$ \\
\hline $\log \beta_{\mathrm{MA}}$ & 20.25 & 19.22 & 18.95 & 18.24 \\
\hline $\log \mathrm{K}_{\mathrm{MAn}}$ & 15.37 & 14.62 & 13.96 & 13.05 \\
\hline рк' & 9.89 & 9.38 & 9.27 & 8.91 \\
\hline & 5.56 & 4.78 & 5.98 & 5.30 \\
\hline
\end{tabular}

Thermodynamic formation constants were obtained by extrapolating the $\log \beta$ vs $\sqrt{ } \mu$ plot to zero ionic strength.

Table 3: Thermodynamic parameters of M(II) - M'(II) - ligand 'A' (DTPA) ternary complexes in equimolar systems along with $\Delta \log \mathrm{K}$ values

\begin{tabular}{|c|c|c|c|c|c|c|}
\hline \multirow{2}{*}{ System } & $20^{\circ} \mathrm{C}$ & \multicolumn{3}{|l|}{$30^{\circ} \mathrm{C}$} & \multirow[b]{2}{*}{$\begin{array}{l}\cdot \Delta \mathrm{H}^{\circ} \\
\mathrm{kJmol}^{-1}\end{array}$} & \multirow[b]{2}{*}{$\begin{array}{c}\Delta \mathrm{S}^{\circ} \\
\mathrm{JK}^{-1} \mathrm{~mol}^{-1}\end{array}$} \\
\hline & $\begin{aligned} \log K(\mu \rightarrow 0) & -\Delta \mathrm{G}^{\circ} \\
& \left(\mathrm{KJ} \mathrm{mol} \mathbf{l}^{-1}\right)\end{aligned}$ & $\log K(\mu \rightarrow 0)$ & $\begin{array}{l}-\Delta \mathrm{G}^{\circ} \\
(\mathrm{kJmol})\end{array}$ & $\Delta \log K$ & & \\
\hline
\end{tabular}

\begin{tabular}{|c|c|c|c|c|c|c|c|c|}
\hline \multicolumn{9}{|c|}{$\mathrm{Cu}(\mathrm{II})-\mathrm{Co}$ (II)-DTPA } \\
\hline $\log \beta$ мам'лH & 24.16 & $\cdot$ & $\dot{15.04}$ & 23.89 & $\cdot$ & -13.57 & $\cdot$ & $\cdot$ \\
\hline $\log \beta_{\text {MMA }}$ & 21.42 & 120.1 & -7.91 & 21.14 & 122.6 & -6.53 & 47.60 & 247.6 \\
\hline $\log \mathrm{K}_{\mathrm{MM}^{\prime} \mathrm{MH}}^{\mathrm{MM}^{\prime}}$ & 14.19 & 79.60 & - & 13.87 & 80.46 & - & 54.39 & 86.04 \\
\hline
\end{tabular}

Thermodynamic formation constants were obtained by extrapolating the $\log \beta$ vs $\sqrt{ } \mu$ plot to zero ionic strength
The value of thermodynamic stability constant, $\mathrm{K} \mu \rightarrow 0$, is used to calculate standard free energy change 


\section{International Journal of Science and Research (IJSR) \\ ISSN (Online): 2319-7064}

Index Copernicus Value (2013): 6.14 | Impact Factor (2015): 6.391

$\left(\Delta G^{\circ}\right)$ for the complexation reaction from van't Hoff isotherm:

$\Delta \mathrm{G}^{\circ}=-2.303 \mathrm{RT} \log \mathrm{K} \mu \rightarrow 0$
Further, standard enthalpy change $\left(\Delta \mathrm{H}^{\circ}\right)$ is calculated by using van't Hoff isochore:

$$
\frac{\mathrm{d}\left(\ln K_{\mu \rightarrow 0}\right)}{d T}
$$

Alternatively this can be represented as:

$$
\log \frac{K_{T_{2}}}{K_{T_{1}}}=\frac{\Delta H^{\circ}}{2 \cdot 303 R}\left(\frac{T_{1}-T_{2}}{T_{1} T_{2}}\right)
$$

The standard entropy change $\left(\Delta \mathrm{S}^{\circ}\right)$ is calculated by using following simple form of Gibb's Helmholtz equation:

$$
\Delta \mathrm{G}^{\circ}=\Delta \mathrm{H}^{\circ}-\mathrm{T} \Delta \mathrm{S}^{\circ}
$$

The values of thermodynamic parameters $\Delta \mathrm{G}^{\circ}$ (free energy change), $\Delta \mathrm{H}^{\circ}$ (enthalpy change) and $\Delta \mathrm{S}^{\circ}$ (entropy change) are given in Table 3.

The qualitative analysis on the basis of the trends of the titration curves are supported by the quantative results obtained by subjecting the experimental data to computational analysis. Speciation curves show the variation of the concentration of different species formed in particular equilibria in the form of percentage distribution against $\mathrm{pH}$. Speciation curves for $\mathrm{Cu}(\mathrm{II})$ Co(II)- DTPA are given in Figure (2.1).

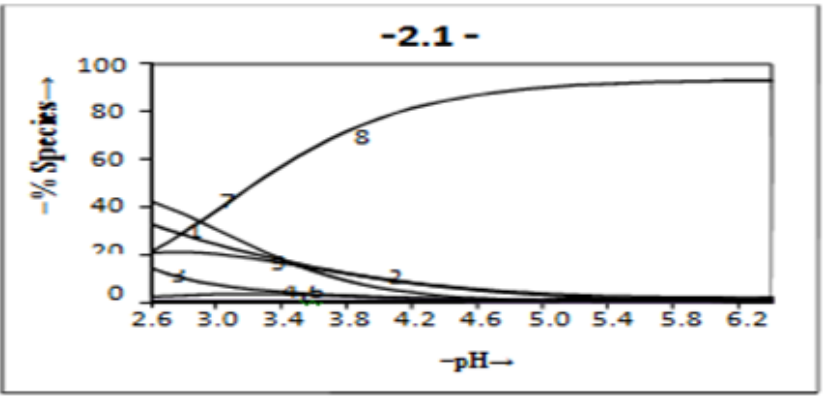

Figure 2.1: $\mathrm{Cu}(\mathrm{II})-\mathrm{Co}(\mathrm{II})-\mathrm{DTPA}$

$(1: 1: 1)$ Systems at $30^{\circ} \mathrm{C}\left(\mu=0.10 \mathrm{M}\left(\mathrm{NaNO}_{3}\right)\right)$.

Where, Curve 1: $[\mathrm{M}] ; 2\left[\mathrm{M}^{\prime}\right] ; 3[\mathrm{MAH}] ; 4[\mathrm{MA}] ; 5$

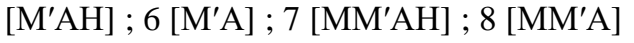

It is noted that the formation of 1:1:1 heterobimetallic ternary complexes occur in $\mathrm{pH}$ range 2.5 to 6.5 . The concentration of binary species is below $35 \%$ in all the cases. However, concentration of ternary species is found to be about $95 \%$. This clearly indicates that in all cases percentage concentration of ternary species (MM'AH and

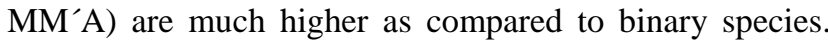
Protonated species is predominant in lower $\mathrm{pH}$ range and its concentration decreases continuously with the increase of $\mathrm{pH}$, whereas concentration of MM'A heterobimetallic complex species increases gradually. Speciation curve also supports the simultaneous co-ordination of both metal ions with ligand.

\section{Conclusion}

From the above discussions it is concluded that the formation of heterobimetallic complexes occurs in a single step through simultaneous coordination of two metal ions and ligand. The metals used in present investigation are bivalent usually having coordination number six

The ligand DTPA is octadentate in nature. So it can be assumed that in binary complexes, the metal ion get coordinated to the ligand by four/ six coordination sites, still leaving vacant coordination sites available for interaction with another metal, thus making the formation of mixed metal complex possible. As stated the percentage formation of ternary complexes is found to be higher in comparison to the binary species. The negative $\Delta \mathrm{G}^{\circ}$ in each case indicates that the complexation is spontaneous. The enthalpy changes are exothermic. The positive values for $\Delta \mathrm{S}^{\circ}$ indicate that complexation reactions are entropically favoured under the experimental conditions.

\section{References}

[1] A. E. Martell and R. M. Smith, Critical Constants-1: Amino acids, New York (1974).

[2] H. Sigel, Metal Ions in Biological Systems-2, MarcelDekker, Inc., New York (1973).

[3] M. T. Beck, Chemistry of Complex Equilibria, Van Nostrand, New York, pp.174-190 (1970).

[4] A.Sigel and H.Sigel, Metal Ions in Biological system, Marcel Dekker, New York, 1971-2001, 1-38.

[5] K.P.Singh, G.K.Mishra and V.Krishna, Proc. Nat. Acad. Sci. India, 2000, 70(A), 233.

[6] V. Joszai, I. Turi, C. Kallay, G. Pappalardo, G. Di Natale, E. Rizzarelli and I. Sovago, J. Inorg. Biochem., 2012, 112, 17-24.

[7] B. Singh and D. Kumar, IJSRP, 2013, 3(2). 


\section{International Journal of Science and Research (IJSR) \\ ISSN (Online): 2319-7064}

Index Copernicus Value (2013): 6.14 | Impact Factor (2015): 6.391

[8] P. Rajathirumoni, P.T. Arasu and M.S. Nair, Indian J. Chem., 1992, 31(A), 760

[9] S.Sinha, V.P.Shukla, P.P.Singh and V.Krishna, Chem.Sci.Trans., 2014, 3(2), 576-581.

[10] M. Devi, R. Nair (Ahuja), S. Kumari Yadav and K. Dwivedi Journal of Chemical, Biological and Physical Sciences2014, 4(3) 1965-1972.

[11] G.K. Mishra., V. Krishna and K.P. Dubey, Proc.Nat. Acad. Sci. India, 1999, 69(A), 19

[12] N. Singh, R.N. Patel, K.K. Shukla and P.K. Singh, Indian J. Chem., 2003, 42(A), 1883.

[13] Chaberek and A.E. Martell, J. Am. Chem. Soc., 1952, $74,5052$.

[14] S. Chaberek and A.E. Martell, J. Am. Chem. Soc., $1955,77,1477$

[15] R.Nayan and A.K.Dey, Indian J. Chem., 14A, 892 (1976).

[16] I.G. Sayce, Talanta, 1968 15, 1397; 1971, 18, 653.

[17] I.G. Sayce and V.S. Sharma, Talanta, 1972, 19, 831 